\title{
Metadata Analysis For Gut Microbiota between Indoor and Street Cats of Malaysia
}

\author{
Darren Dean Tay¹, Shing Wei Siew¹, Mohd Najib Bin Razali2,3, Hajar Fauzan Bin Ahmad1,4 \\ ${ }^{1}$ Faculty of Industrial Science Technology, Universiti Malaysia Pahang, 26600 Pahang, Malaysia. \\ ${ }^{2}$ Faculty of Chemical and Process Engineering Technology, Universiti Malaysia Pahang, 26600 Pahang, Malaysia. \\ ${ }_{3}^{3}$ MNR Multitech Sdn. Bhd, UMP Holdings Complex, 26300 Gambang, Malaysia. \\ ${ }^{4}$ Centre for Research in Advanced Tropical Bioscience (Biotropic Centre), Lebuhraya Tun Razak, 26300 Gambang, Malaysia.
}

\begin{abstract}
With the advancement of sequencing technology, the studies related to the complex nature of microbial communities are possible to be untapped. The goal of this study is to perform a comparison between the composition of bacteria between the gut of Malaysian indoor and street cats. For this research, stool samples of the cats were collected where the genomic DNA were extracted using DNeasy PowerSoil Pro Kit. The extracted DNA were sequenced by targeting the bacterial community using primers from V4 region of $16 \mathrm{~S}$ rRNA. The raw data were analysed using QIIME2 to obtain the diversity, taxonomy, and differential abundance between the groups. Here, we found that indoor and street cats have similar alpha diversity $(p>0.05)$, with slight differences between the groups based on the bacterial composition. Likewise, the beta diversity suggest that the two groups are similar to each other. The genus Bifidobacterium, Clostridium, Collinsella, Enterococcus, Cantenibacterium and Lactobacillus from phylum Firmicutes while were found to be more abundant in indoor cats while street cats had more of the phylum Actinobacteria from the genus of Acinetobacter, Blautia, and Olsenella. Hence, we observed whether a cat is kept indoor or is a stray does not significantly cause a shift in their respective microbiota composition.
\end{abstract}

\section{ARTICLE HISTORY}

Received: $09^{\text {th }}$ July 2020

Revised: $25^{\text {th }}$ Nov 2020

Accepted: 31 st Mar 2021

\section{KEYWORDS}

QIIME2

Gut microbiome

Bacteria

Malaysia

\section{INTRODUCTION}

Microbiota is known as a microbial community that shares either commensalism, mutualistic or pathogenic relationships. Over the years, studies on the composition of gut bacteria have focused on human models [1], [2] with lesser attention on other kingdoms like animal, plant, and the environment. Recently, studies on mammals such as dogs and cats are getting highlights as these animals are kept as human beings' pets and inhibit the same living quarters. Through evolution, these animals have adapted over time to be more domesticated and reliant on humans while also having notable changes to their physical structures [3]. Recent studies documented that the gut of mammalian pets are home to bacteria under the phylum of Firmicutes, Bacteroidetes, Actinobacteria, Fusobacteria and Proteobacteria, respectively. At the genus level, they are well-defined as Clostridium, Lactobacillus, Blautia and Collinsella [4]. The interactions between gut microbiota and the host are involved in many bodily functions, such as digestion, host metabolism, vitamins synthesis, biotransformation of bile acids, xenobiotics metabolism, correct maturation of gastrointestinal cells, autoimmunity and defence against pathogenic bacteria [5], [6].

Several factors were identified to affect the microbiome composition [7], for which mounting evidence showed that environments and diets [8], [9] manifested a significant impact in shaping the composition of microbiota in the animals as host. This including in shaping the well-being and health status of the hosts. However, the host's surroundings also play important roles in contributing to the host bacterial composition. Here, we hypothesized the street cats would harbour a more diverse microbiome given their exposure to outside environments, while their counterparts would display less diversity due to fixed diets provided by an owner. Therefore, the objective of this study is to observe the composition gut microbiome in relation to the cat's surroundings.

Here, we adopted the independent culture method, where the stool samples of indoor and outdoor cats were collected and extracted using the DNeasy PowerSoil Pro Kit. The extracted DNA was quantified to measure DNA quality. Then, PCR was performed and sequenced, which targeted the bacterial community primers for V4 region of 16S rRNA. The generated data were analyzed using QIIME2 to obtain the diversity, taxonomy, and differential abundance between the groups. In conclusion, the data produced from this study can be further expanded upon in the near future to identify other factors that can potentially affect a cat's gut microbiome. 


\section{MATERIALS AND METHODS}

\section{Sample Collection}

All felines in this investigation were randomly picked from the volunteers that offered their aid for this study. Feline stools were obtained arbitrarily by a collaborator for this study a day before collection time. No animals were harmed nor tested during the entire study. All sample were gathered and used for the study with verbal proprietor assent who knew that the samples were being used for research purpose. Ten samples were collected altogether by the collaborator for this study, with age samples ranging from 6 months to 3 years old. Five of the samples were from indoor cats, while the other 5 were from street cats. Both stool samples were collected from a housing area at Kuantan, Pahang. The collaborator recorded relevant information regarding the indoor cats used for the study from their respective owners. The owners gave these cats only commercial foods for seven days upon request before the sample collection. Samples obtained were placed in a properly labelled screw-top container and refrigerated. The street cat stool sample was collected by the collaborator around the residential area regardless of collection time. The stool samples were found close to an alley where many street cats were often seen gathered. These stools were selected from the impurities and collected via disposable spoons. Samples were kept in a sealed bag in a chiller for subsequent analysis and stored in a freezer at $-20^{\circ} \mathrm{C}$ before microbial analysis. Another population-based optimization algorithm is the gravitational search algorithm (GSA). GSA was designed according to the Newtonian gravity law and mass interactions. In the algorithm, agents and their performance is evaluated by their masses which rely on fitness function values. The location of each agent in the search space indicates a problem solution. The heaviest mass is the optimum solution in the search space, and by lapse of time, masses are attracted by the heaviest mass and converged to the better solution.

\section{DNA Extraction, Library Preparation \& DNA Sequencing}

The genomic DNA was extracted using DNeasy Powersoil Pro Kit according to the manufacturer's provided protocol with a modification [10]. Amplicon libraries were created using two-steps custom PCR protocols targeting the V4 region of $16 \mathrm{~s}$ rRNA as described previously: 515fB (5' GTGYCAGCMGCCGCGGTAA 3') and 806rB (5' GGACTACNVGGGTWTCTAAT 3') [11]. Briefly, the 16S rRNA V4 region was amplified using OneTaq ${ }^{\circledR} 2 \mathrm{X}$ Master Mix (NEB, Ipswich, USA) from the extracted gDNA using the primer pair 515F-806R [1] containing a partial Illumina Nextera adapter in their $5^{\prime}$ end. The PCR condition used was $94^{\circ} \mathrm{C}-30$ seconds followed by 30 cycles of $94^{\circ} \mathrm{C}-15$ sec, $50^{\circ} \mathrm{C}-15 \mathrm{sec}$ and $68^{\circ} \mathrm{C}-30$ seconds. The PCR products were cleaned using GeneSEQ magnetic beads and subsequently used for the index PCR reaction to incorporate dual-index barcode and the remaining Illumina adapter. The index PCR products were pooled, bead-purified and quantified using Denovix high-sensitivity fluorescence quantification kit (Denovix, Delaware, USA). The library was sequenced on an iSeq100 (Illumina, San Diego, CA) located at GeneSEQ Sdn Bhd using the run configuration of $1 \times 300 \mathrm{bp}$ as per the recommendation for $16 \mathrm{~S} \mathrm{~V} 4$ sequencing on this system (https://help.ezbiocloud.net/16s-mtp-protocol-for-illumina-iseq-100/).

\section{Metadata Analysis}

Metadata analysis was conducted from an Acer laptop with an Intel(R) Core(TM) i5-4200 CPU @ 1.60GHz 2.30GHz processer, 7.88GB usable RAM, and uses a system type of 64-bit operating system, x64-based processor. 10 FASTQ folders containing the DNA sequences of the 10 cat samples were obtained from the sequence provider and imported into the virtual computer hosting the QIIME2 pipeline. No demultiplexing was done as the sequences provided were already in demultiplexed format. Visual analysis was conducted on the sequences imported to determine the cut-off read lengths. Sequences are subjected to denoising using the q2-dada2 plugin, and a feature table was created. A phylogenetic tree was constructed using the q2-phylogeny plugin that is present within QIIME2. Alpha and beta diversity metrics were produced through the q2-diversity plugin. Diversity metric artefacts of the following metrics were created: Shannon's diversity index, Observed Features, Faith's Phylogenetic Diversity, Pielou's Evenness, and PCoA plots for Jaccard distance, BrayCurtis distance, unweighted UniFrac distance and weighted Unifrac distance. PCoA plots were generated through Emperor for each of the beta diversity metrics. Alpha rarefaction plot was created using the visualizer QIIME diversity alpha-rarefaction. A parameter of --p-max-depth 16200 was set as it was close to the median value of the feature table. Taxonomy was assigned using the q2-feature-classifier plugin found within QIIME2. A pre-trained Naïve Bayes classifier trained on the Greengenes 13_8 99\% OTUs (https://data.qiime2.org/2020.11/common/gg-13-8-99-515-806-nbclassifier.qza) was used to assign taxonomy. Differential abundance analysis was done using ANCOM, ALDEx2, and Songbird.

\section{Metadata Analysis}

Genomics data that were generated for Malaysian Feline Microbiome Study [12] are available online via https://doi.org/10.6084/m9.figshare.14397572.v1. The metadata file is available from the corresponding author on reasonable request. 


\section{RESULTS AND DISCUSSION}

\section{Study Subject Description}

As mentioned previously in the methodology, the collaborator collected the background information of the subjects by either interviewing the owners or by observing the behaviours of street cats that roamed the housing area. From Table 1 , the age for indoor cats were 5.6 months, 6 months, 1.6 years, 2.5 years, and 3.5 years. The gender observed between the indoor subjects are equally split with 3 females and 2 males, while the weights observed showed that cats ranged between $5 \mathrm{~kg}$ to $2 \mathrm{~kg}$, which meant that the cats were healthy based on their respective ages. This is also confirmed by the general health statement provided by their owners. The owners also provided the activeness of the cats. The indoor cats were also fed on an average frequency of twice per day with mixed commercial wet and dry foods apart from subject c1 whose diet mainly consisted of wet and boiled fish due to its picky nature. The cats' breeds were mostly a domestic short hair except for two other breeds, a domestic mixed and a Turkish Van. Thus, with consideration of the data generated from subject $\mathrm{c} 1$, it can be said that the 5 samples selected for indoor cats can roughly reflect the general background of most indoor cats found typically in Malaysian homes.

However, many of the data categories had to be labelled as not available (n/a) due to the inability to gain more information regarding the outdoor cat samples. Nevertheless, despite not having clear information about the outdoor cats' age by basing assumptions on the stool samples collected by the collaborator, the samples were all roughly from adult cats as it is very unlikely to find kitten stools. Similarly, an assumption can be made that, at the very least, these subjects consume food scraps that are available to them and the cheap dry cat foods provided to them by the surrounding community.

All the breed used for outdoor cat samples were of domestic short hair. Thus, based on the information present, there is no clear indication that it can be confidently stated that the 5 samples selected for outdoor cats will reflect the general background of most outdoor cats found in Malaysia. This is mainly due to the random nature of most outdoor cats in the first place. This study does focus on whether cats were kept indoors or if they are street cats, and as such, the lack of information in the outdoor cats' dataset will not affect the outcome of the study much. However, the lack of information does indicate that no other factors can be used to correlate their relationship with the composition of bacteria found within the gut of cats.

Table 1. Data obtained regarding cat subjects from collaborator.

\begin{tabular}{|c|c|c|c|c|c|c|c|c|c|}
\hline $\begin{array}{r}\text { Sa } \\
\text { mple- } \\
\text { id }\end{array}$ & $\begin{array}{l}\text { treat } \\
\text { ment }\end{array}$ & age & $\begin{array}{l}\text { gend } \\
\text { er }\end{array}$ & breed & $\begin{array}{r}\text { weig } \\
\text { ht }(\mathrm{kg})\end{array}$ & $\begin{array}{l}\text { healt } \\
\text { h }\end{array}$ & $\begin{array}{l}\text { activi } \\
\text { ty level }\end{array}$ & diet & $\begin{array}{l}\text { meal } \\
\text { s per } \\
\text { day }\end{array}$ \\
\hline c1 & $\begin{array}{l}\text { indoo } \\
\mathrm{r}\end{array}$ & $\begin{array}{r}1.6 \\
\text { years }\end{array}$ & $\begin{array}{l}\text { femal } \\
\text { e }\end{array}$ & $\begin{array}{l}\text { domes } \\
\text { tic short } \\
\text { hair }\end{array}$ & 5 & good & $\begin{array}{l}\text { very } \\
\text { active }\end{array}$ & $\begin{array}{c}\text { wet } \\
\& \text { boiled } \\
\text { fish }\end{array}$ & $1-3$ \\
\hline c2 & $\begin{array}{l}\text { indoo } \\
\mathrm{r}\end{array}$ & $\begin{array}{r}5.6 \\
\text { months }\end{array}$ & $\begin{array}{l}\text { femal } \\
\text { e }\end{array}$ & $\begin{array}{l}\text { domes } \\
\text { tic mix }\end{array}$ & 2 & good & $\begin{array}{l}\text { very } \\
\text { active }\end{array}$ & $\begin{array}{l}\operatorname{mixe} \\
\mathrm{d}\end{array}$ & $2-3$ \\
\hline c3 & $\begin{array}{l}\text { indoo } \\
\mathrm{r}\end{array}$ & $\begin{array}{c}6 \\
\text { months }\end{array}$ & male & $\begin{array}{l}\text { domes } \\
\text { tic short } \\
\text { hair }\end{array}$ & 2 & fair & $\begin{array}{l}\text { activ } \\
\text { e }\end{array}$ & $\begin{array}{l}\operatorname{mixe} \\
\mathrm{d}\end{array}$ & 2 \\
\hline c4 & $\begin{array}{l}\text { indoo } \\
\mathrm{r}\end{array}$ & $\begin{array}{r}2.5 \\
\text { years }\end{array}$ & male & $\begin{array}{l}\text { domes } \\
\text { tic short } \\
\text { hair }\end{array}$ & 5 & good & $\begin{array}{l}\text { avera } \\
\text { ge }\end{array}$ & $\begin{array}{l}\operatorname{mixe} \\
\mathrm{d}\end{array}$ & 2 \\
\hline c5 & $\begin{array}{l}\text { indoo } \\
\mathrm{r}\end{array}$ & $\begin{array}{r}3.5 \\
\text { years }\end{array}$ & $\begin{array}{l}\text { femal } \\
\text { e }\end{array}$ & $\begin{array}{l}\text { Turkis } \\
\text { h van }\end{array}$ & 4 & good & $\begin{array}{l}\text { avera } \\
\text { ge }\end{array}$ & $\begin{array}{l}\operatorname{mixe} \\
\mathrm{d}\end{array}$ & 2 \\
\hline c6 & $\begin{array}{l}\text { outdo } \\
\text { or }\end{array}$ & $\mathrm{n} / \mathrm{a}$ & $\mathrm{n} / \mathrm{a}$ & $\begin{array}{l}\text { domes } \\
\text { tic short } \\
\text { hair }\end{array}$ & $\mathrm{n} / \mathrm{a}$ & $\mathrm{n} / \mathrm{a}$ & $\mathrm{n} / \mathrm{a}$ & $\mathrm{n} / \mathrm{a}$ & $\mathrm{n} / \mathrm{a}$ \\
\hline c7 & $\begin{array}{l}\text { outdo } \\
\text { or }\end{array}$ & $\mathrm{n} / \mathrm{a}$ & $\mathrm{n} / \mathrm{a}$ & $\begin{array}{l}\text { domes } \\
\text { tic short } \\
\text { hair }\end{array}$ & $\mathrm{n} / \mathrm{a}$ & $\mathrm{n} / \mathrm{a}$ & $\mathrm{n} / \mathrm{a}$ & $\mathrm{n} / \mathrm{a}$ & $\mathrm{n} / \mathrm{a}$ \\
\hline c8 & $\begin{array}{l}\text { outdo } \\
\text { or }\end{array}$ & $\mathrm{n} / \mathrm{a}$ & $\mathrm{n} / \mathrm{a}$ & $\begin{array}{l}\text { domes } \\
\text { tic short } \\
\text { hair }\end{array}$ & $\mathrm{n} / \mathrm{a}$ & $\mathrm{n} / \mathrm{a}$ & $\mathrm{n} / \mathrm{a}$ & $\mathrm{n} / \mathrm{a}$ & $\mathrm{n} / \mathrm{a}$ \\
\hline c9 & $\begin{array}{l}\text { outdo } \\
\text { or }\end{array}$ & $\mathrm{n} / \mathrm{a}$ & $\mathrm{n} / \mathrm{a}$ & $\begin{array}{l}\text { domes } \\
\text { tic short } \\
\text { hair }\end{array}$ & $\mathrm{n} / \mathrm{a}$ & $\mathrm{n} / \mathrm{a}$ & $\mathrm{n} / \mathrm{a}$ & $\mathrm{n} / \mathrm{a}$ & $\mathrm{n} / \mathrm{a}$ \\
\hline
\end{tabular}




\begin{abstract}
outdo $\mathrm{n} / \mathrm{a}$
\end{abstract} or $\mathrm{n} / \mathrm{a}$ domes tic short

hair $\mathrm{n} / \mathrm{a} \quad \mathrm{n} / \mathrm{a}$ $\mathrm{n} / \mathrm{a}$ $\mathrm{n} / \mathrm{a}$ $\mathrm{n} / \mathrm{a}$

\section{Diversity Analysis}

Sampling depth used does not remove any samples from the core metrics analysis. Alpha diversity testing is signified by several matrices such as Shannon's Diversity, Observed Features, Faith's Phylogenetic Diversity, and Pielou's Evenness Index, which are portrayed as two boxplots for the two treatment groups with indoor cats on the left side and street or outdoor cats on the right side in Figure 1. Generally, it can be seen among the four boxplot graphs, the indoor cats seemed to show better species diversity than those who live in the street. This can be indicated by the higher median score shown in the three parameters. The only exception to this would be Pielou's Evenness which suggest the inverse of the previous statement. However, Pielou's Evenness does contain an outlier, so it may not be an accurate representation of alpha diversity found within street cats. The p-values for each Kruskal Wallis test can be found in Table 2. Since all pvalues obtained are greater than 0.05 , there is no significant difference for species richness between the two treatment groups. However, all the results before this show that indoor cats have slightly better diversity and go against the initial hypothesis.

Table 2. P-values of Kruskal Wallis test for each metric.

\begin{tabular}{cc}
\hline Metric & P-value \\
\hline Shannon & 0.916815 \\
Observed Features & 0.752567 \\
Faith & 0.117185 \\
Evenness & 0.754023 \\
\hline
\end{tabular}

This higher diversity seen in indoor cats is probably due to the benefits of having a stable food source and the possible interactions with their owners or other cat members within the household [13]. Despite the fact these cats mainly were kept indoors, this does not hinder the fact that they most frequently encounter household members that do venture outside. Since cats have shown the capability to influence the human microbiome, the inverse could be possible. In short, indoor cats have the best of both worlds as they continuously have access to food, leading to an overall healthier gut and gaining exposure to other microbes that normally be absent for them due to their interactions with house members. These factors are probably the biggest contributor to indoor cats' slightly higher diversity.

Beta diversity for the four metrics; Bray-Curtis distance, Jaccard distance, Unweighted UniFrac distance, and Weighted UniFrac distance, were shown as PCoA plots in Figure 2. Both Bray-Curtis and Jaccard distance would suggest that a majority of the two groups are similar to one another as there are 6 points on the plot that are relatively close to each other, which is composed of equally both indoor and outdoor samples. Both Weighted and Unweighted UniFrac distance shows something similar, and many points that represent both groups are also fairly close to one another. This would suggest that the bacterial composition between indoor cats and outdoor cats are not that different from one another. This suggestion can be further explored by inspecting the p-value obtained from the PERMANOVA test, which is 0.188 . Based on this, there are no significant differences between the treatment groups, and they are similar to each other. This would suggest that might not be any significant difference between the two groups.

This could be due to the reality that street cats are just as well taken care of as indoor cats. Within Malaysia, it very common that street cats flock towards humans for basic needs. This is because of the culture of its citizens that treasures and takes care of cats regardless of their ownership status. Many would feed stray cats despite not housing them themselves. When asked about the community within the area of study, the same culture was also observed. Many residents would routinely feed the street cat around the area with dry pet food commonly found at stores despite not owning cats. This paired up with the fact most indoor cats would sometimes also interact with the street cats, would result in a similar gut composition to cats that would be staying indoor albeit with lower diversity. The lower discussed alpha diversity is most probably linked to the cheap food provided to these street cats. To obtain a truly split microbiome composition between the two groups, street cats used for the analysis would have to be feral cats with no human contact and would routinely scavenge for food. This would be a hard thing to achieve in Malaysia, given the pre-established culture surrounding cats.

Additionally, alpha rarefaction was conducted to evaluate the utility of sampling depth at 10000 . Here, we observed any sampling depth chosen beyond the set amount would not yield any additional results. This means that all diversity present within all 10 samples were able to be achieved. The graphical data related to this evaluation is not shown in this study. 
(a)

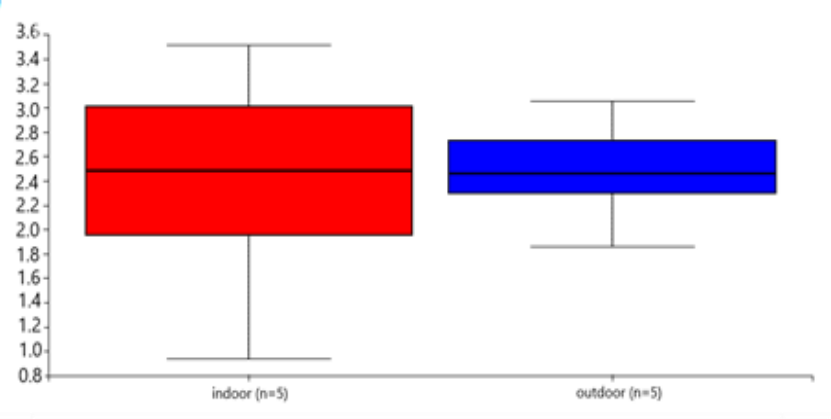

(c)

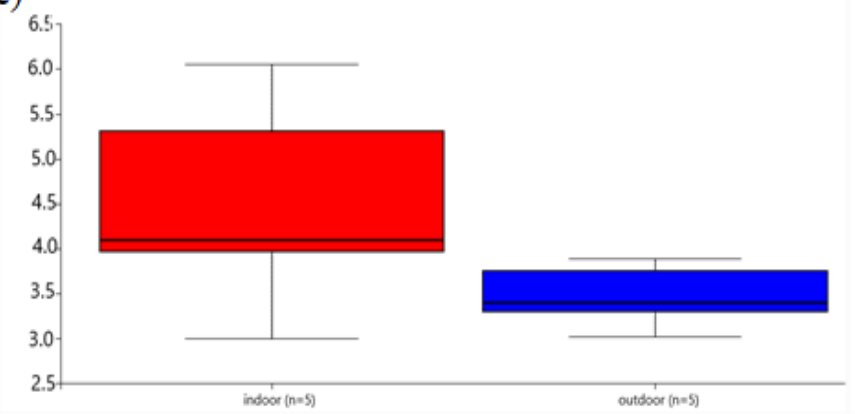

(b)

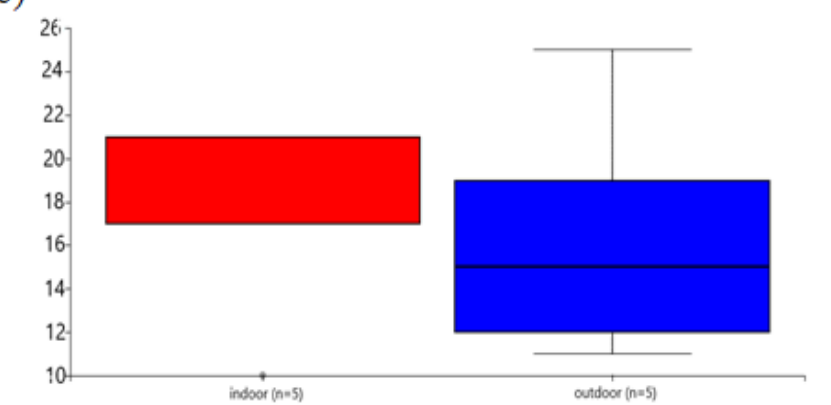

(d)

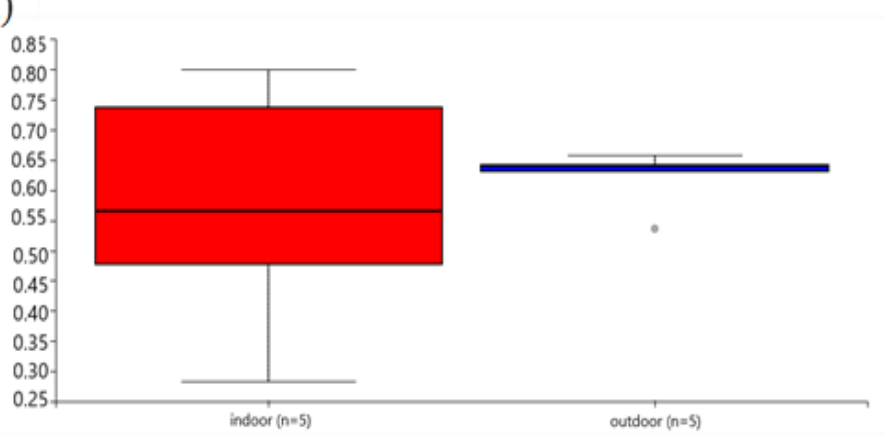

Figure 1. Visualization of alpha diversity (a) Shannon's Diversity Index; (b) Observed Features; (c) Faith's Phylogenetic Diversity; (d) Pielou's Evenness. Red represents indoor groups, while blue is outdoor groups.

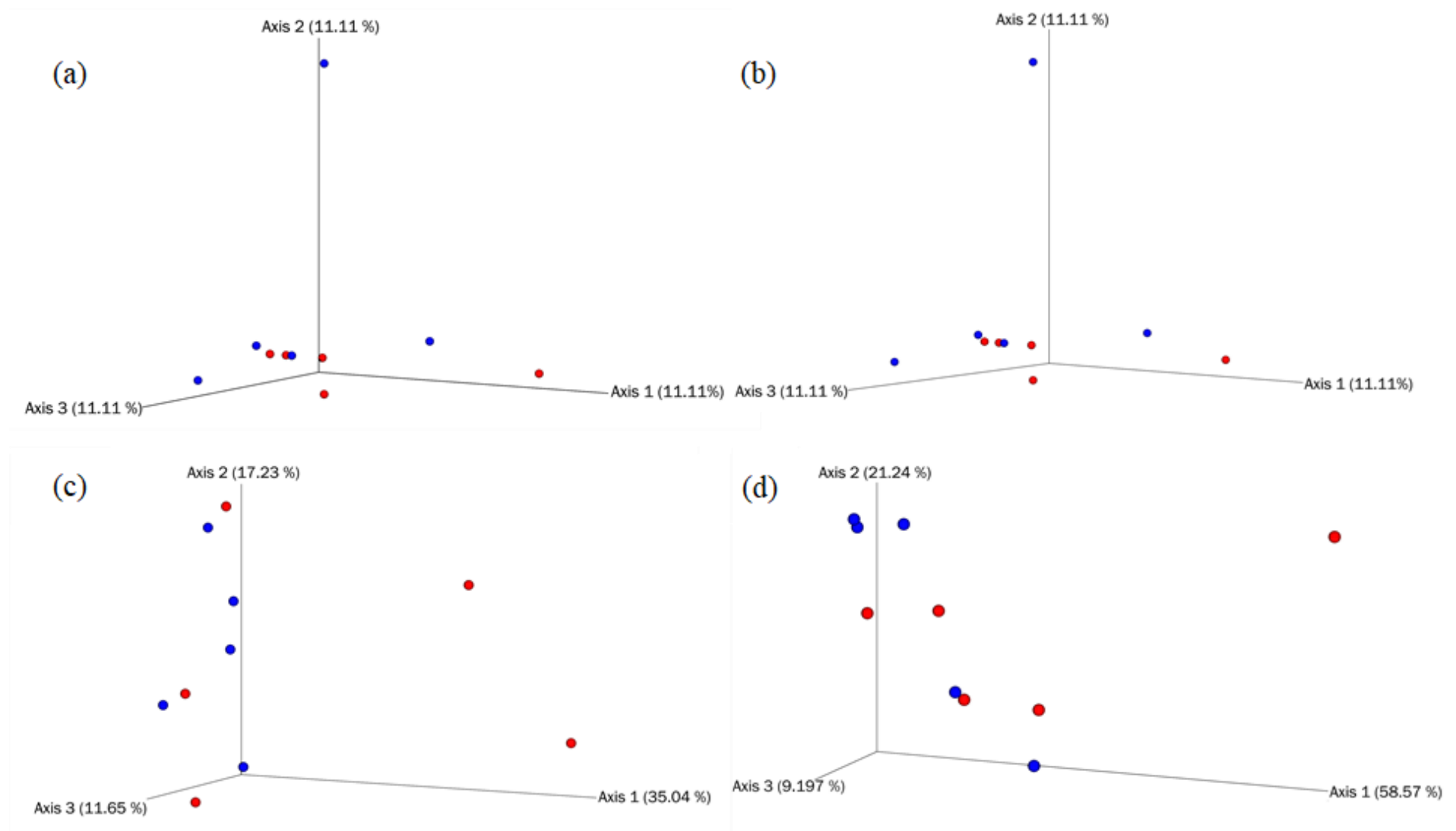

Figure 2. PCoA plot of (a) Bray-Curtis distance, (b) Jaccard distance, (c) Unweighted UniFrac distance, (d) Weighted UniFrac distance using Emperor. Red dots are indoor while blue is outdoor. 


\section{Taxonomy Analysis}

The taxonomy analysis results can be found in Figure 3 and 4, which are summarized versions of graphs results obtained from the QIIME2 pipeline using Microsoft Excel for better clarity. The results showed a very different composition than the norm instead, where Firmicutes seemed to be the most abundant phylum still. However, Proteobacteria is almost non-existent within the other samples. Fusobacteria and Bacteroidetes were also barely seen across all the samples. Surprisingly, Actinobacteria seemed to be very abundant in almost all the samples collected. It was found that indoor cats generally had more Firmicutes while outdoor cats had more Actinobacteria. This spilt in the difference of abundance could mostly be attributed to the circumstances that surround the cat [14]. Since outdoor cats are more subjected to the outside surroundings, which likely contains many pathogens, it makes logical sense that they would have more actinobacteria to combat the increased presence of said pathogens. The higher abundance of Firmicutes presents within indoor cats due to their mixed diet and constant food source. Given that indoor cats are generally fed decent quality food, it is no wonder many Firmicutes are able to thrive given their association of producing components utilized by the host daily [15]. One sample, though, showed that Proteobacteria was more present than Firmicutes. This sample was $\mathrm{c} 1$ which was taken from a very picky cat, according to its owner. The owner describes that the cat often only eats specific foods such as wet-based pet food or boiled fish, indicating its unique microbiome composition compared to the other samples.

As for the genus level, indoor cats had a higher abundance of the genus Bifidobacterium, Clostridium, Collinsella, Enterococcus, Cantenibacterium and Lactobacillus in comparison to outdoor cats. Conversely, outdoor cats were observed to have a higher abundance of Acinetobacter, Blautia, and Olsenella. The presence of Clostridium in large numbers is often linked to diseases [16], and the same can be said for the genus Cantenibacterium [17]. Lactobacillus is often linked to a healthy gut and function to help combat diseases within the body [18]. The genus Bifidobacterium function within the body to help digest fibres and produce SCFA but also aids to prevent disease infection within the host. Similarly, Enterococcus can also be associated with fighting off pathogens as it produces bacteriocin [19]. However, the genus Collinsella has many interactions within the body. Some sources point to it to be related to obesity, while others highlight its capability to cure or alleviate certain conditions. The genus Blautia on the other hand, is important for the synthesis of butyric and acetic acid, which is used to help reduce obesity. The other genus, Olsenella, is often linked to oral health issues found within humans [20], while the genus Acinetobacter is often associated with the cause of certain infections.

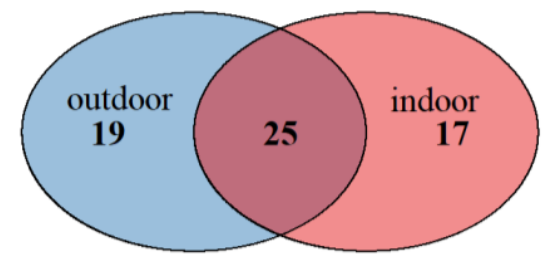

Figure 3. Venn diagram of bacterial species shared/not shared between indoor and outdoor groups

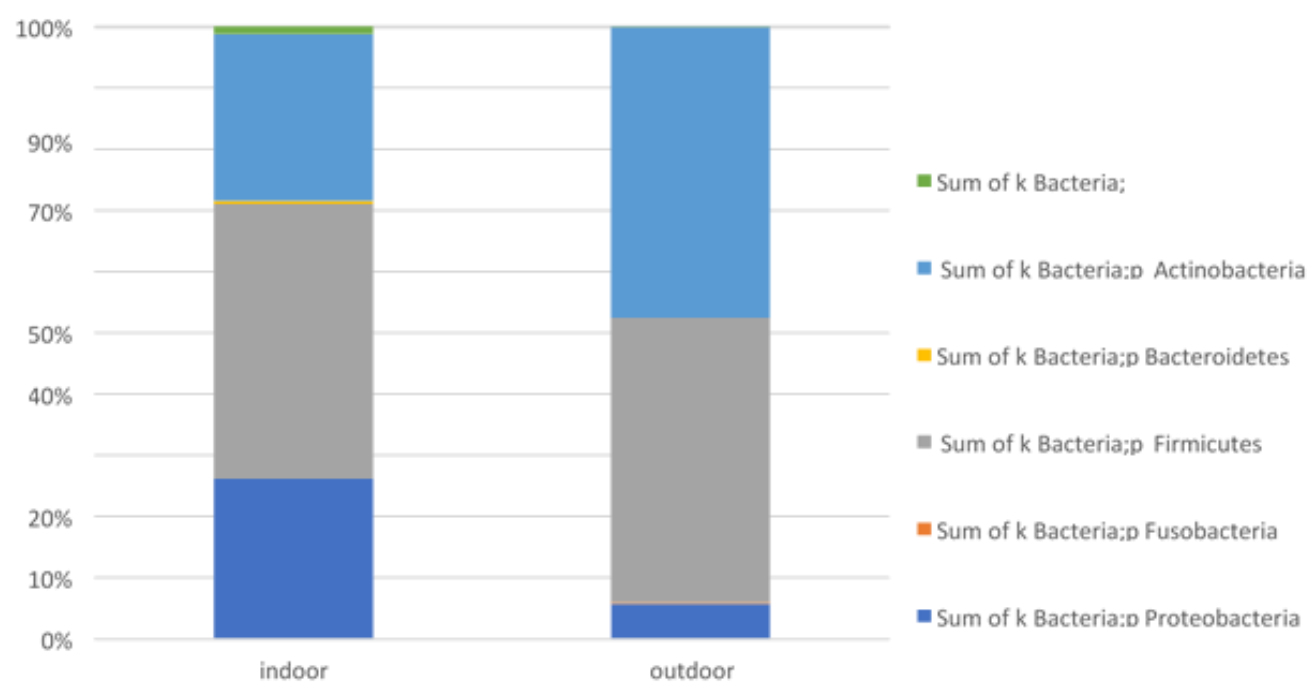

Figure 4. Taxonomy bar plot of bacteria at the phylum level. 
In indoor cats, the presence of the genus Clostridium and Cantenibacterium seem to indicate a pathogenic relationship with the host [21]. However, it is more likely to assume that the presence of these groups is more focused on stimulating the immune response of the cats. Conversely, the genus Bifidobacterium, Lactobacillus and Enterococcus function to defend the host from pathogens and could be reducing the impact of the previously mentioned genus groups. However, due to the odd nature of interactions for Collinsella, there is no clear indication of its role within indoor cats as it could be the source of some cats gaining weight while it may serve as a medical solution for others. As for outdoor cats, the genus Acinetobacter and Olsenella, both seems to have a pathogenic relationship between the cat where Acinetobacter is likely the cause of many infections that the outdoor cat can potentially suffer from while the latter would most likely cause oral issues for the cats.

Interestingly, the genus Blautia is linked with weight loss and could be potential reasoning why some outdoor cats can maintain a leaner and more agile body despite being constantly fed by the community [22]. While there is also the large presence of Ignatzschineria in the data of indoor cats, all of the species originate from one sample, which was c1, who had a very picky diet. The genus is not considered in the analysis despite the high presence count since it would introduce bias to the analysis and would not accurately represent the composition of microbiomes between the two study groups. One thing to note is that some of the sequence's species could not be identified at a genus level. These are the results of the pre-trained classifier used for the taxonomy study. To achieve better results, classifiers can be trained ahead of time on specific databases.

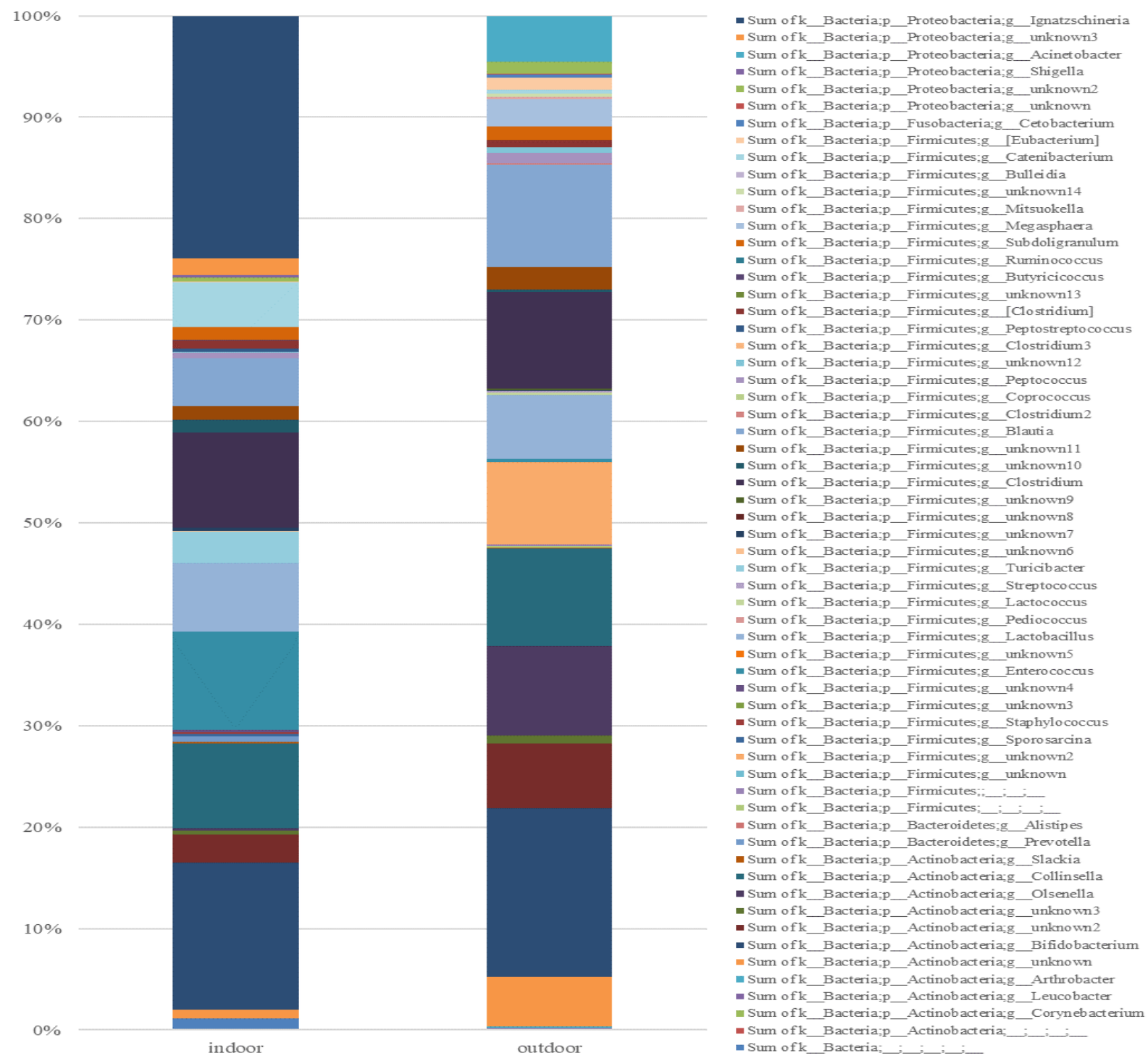

Figure 5. Taxonomy bar plot of bacteria at the genus level. 


\section{Differentially Abundant Analysis}

Differential abundance was done using two different plugins, which were q2- composition for ANOVA method and the q2-aldex2 plugin. The q2-birdson plugin was used to verify the results further. As shown in Figure 6, no significant features are observed using both the ANOVA and ALDEx2 method. This supports the claim made in beta diversity that there are likely no significant differences between the gut microbiome of indoor and outdoor cats. As such, both groups are deemed statically similar to one another. Figure 6(c) shows the regression curve produced from the model, which dictates the quality of the model produced. Ideally, the curve observed should be flattening to show the model fitting perfectly to the data. Figure 6(d) shows the loss curve produced from the model. The curve should also experience flattening and should draw close to zero as much as possible. This would indicate that minimal loss of data was achieved. The blue line represents the model created while the orange line the null model created. The ideal visual produced when these two models are combined to see that the orange line is positioned higher than the blue line, which means that model is performing to our standard or, at the very least, the model is learning something. The value of the Q2 observed also explains the general quality of the results. However, as observed, most of the ideal situations were not found with the results at all. As shown, the graph observed does experience any flattening but instead increases at the very tip after experiencing a drop. This would indicate that the model is overfitting to the data, which is not ideal. Changing the values used for the iterations and differential-prior can help to alleviate the issue. However, despite using multiple different sets of parameters, the model still overfits the data provided. Furthermore, from the same figure, it can be seen that model produced is positioned higher than the null model, which means it is underperforming compared to the null model. The final insight can be gained by looking at the Q2 value, which is - 0.002490 . The ideal value to be achieved would be close to 1 . However, the value obtained would indicate the model produced from using "treatment", which is the parameter to differentiate between indoor and outdoor cats, overfits to data. Additionally, it also means that the model did not learn anything and that factor "treatment" does not play a significant role within the data set.

To summarize, there are no significant features that were observed between indoor cats and outdoor cats. According to the Songbird results, whether cats are kept indoors or outdoors does not play a significant role in the composition of bacteria according to the samples obtained. It should be noted that this may ring true due to the previously mentioned habits of Malaysians that care for felines equally. The study should be repeated using feral and domesticated cats, the data obtained would be significantly different.

(a)

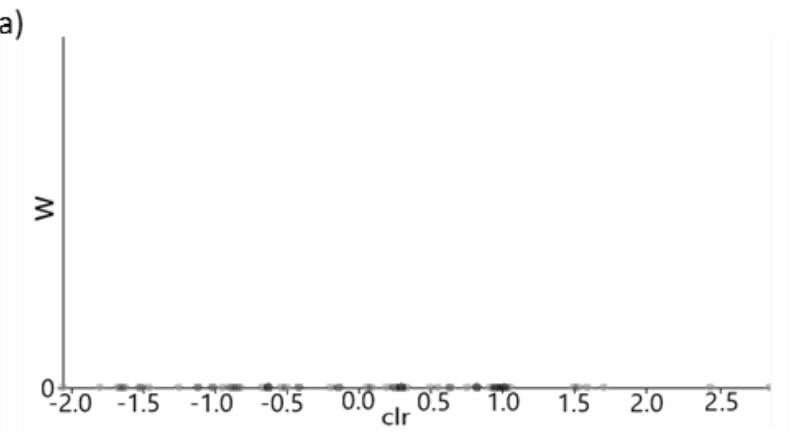

Pseudo Q-squared: $\mathbf{- 0 . 0 0 2 4 9 0}$

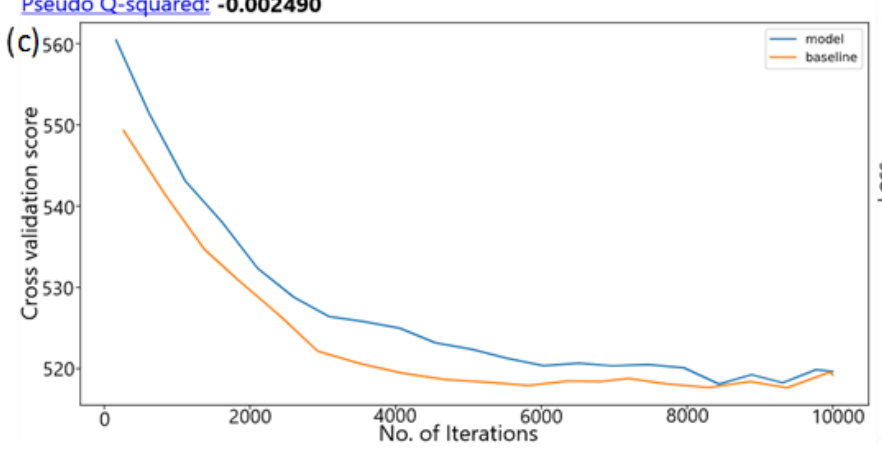

(b)
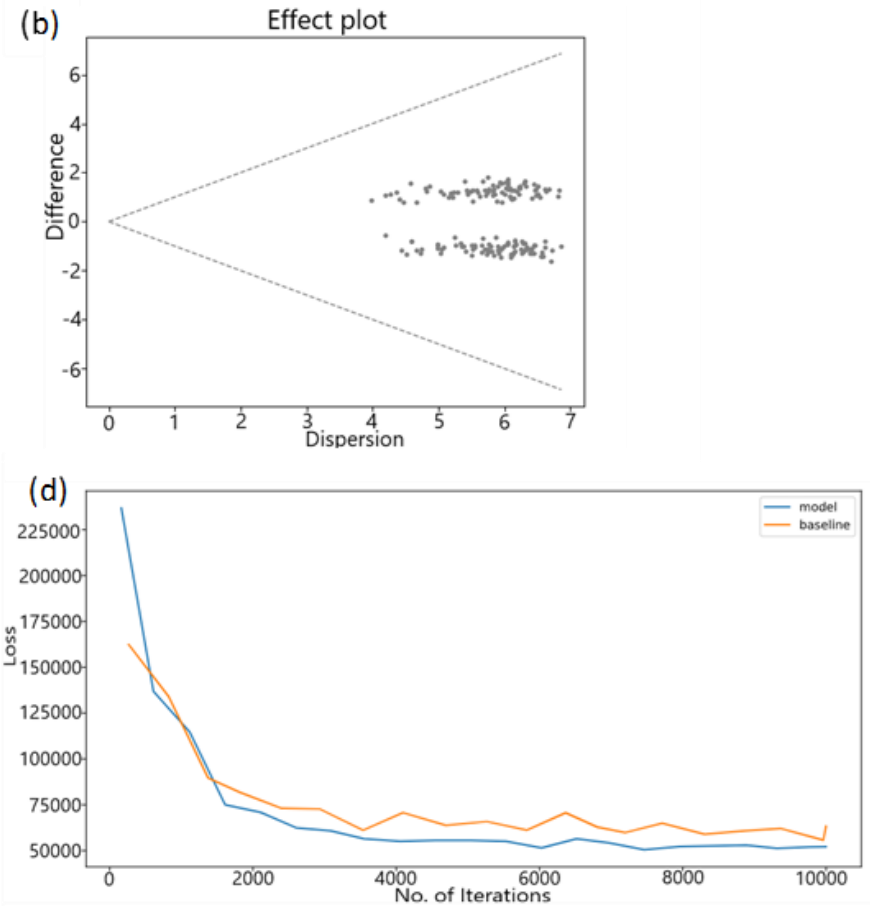

Figure 6. (a) Volcano plot of ANCOM results for genus level; (b) Effect plot result from ALDEx2; (c) Regression curve and (d) Loss curve produced from the model in Birdsong. 


\section{CONCLUSION}

The composition of gut microbiota within indoor cats and street was able to be determined. Results showed that indoor cats and outdoor cats have the same alpha diversity. However, composition wise indoor cats have slightly more differences than street cats thanks to their diet and interactions between household members. Beta diversity analysis shows that the two groups were very similar when compared to each other. Indoor cats were very similar to one another, but street cats were very different from each other. Based on the taxonomic analysis, indoor cats had a higher abundance of the phylum Firmicutes, while street cats had a higher abundance for phylum Actinobacteria. On a genus level, it was found that indoor cats were richer in the genus Bifidobacterium, Clostridium, Collinsella, Enterococcus, Cantenibacterium and Lactobacillus than outdoor cats. Outdoor cats were found to have a higher abundance of Acinetobacter, Blautia, and Olsenella than indoor cats. It is also believed that keeping a cat indoors or outdoors does not significantly shift its microbiota composition.

\section{ETHICS STATEMENT}

The cats in this study were examined during routine care of the owners of the indoor cat group. No treatment decisions were made based on the results of this test. All samples were collected and used for this analysis with verbal owner consent who were aware that these samples were taken for research purpose only.

\section{AUTHOR CONTRIBUTION}

Hajar Fauzan bin Ahmad was the principal investigators and was responsible for the original ideas of the project. Darren Dean Tay and Shing Wei Siew conducted the experiments. Darren Dean Tay and Shing Wei Siew analyzed the data and draft the manuscript. Hajar Fauzan Bin Ahmad Darren Dean Tay, Shing Wei Siew, Mohd Najib Bin Razali revised and edited the manuscript. All authors have read and approved the final manuscript.

\section{ACKNOWLEDGEMENT}

The authors would like to thank Universiti Malaysia Pahang and Supercat International Sdn. Bhd. for UMP-MTUN Industry Matching Grant RDU192802/UIC190812, and cat owners who participated in this study.

\section{REFERENCES}

[1] H. F. Ahmad et al., "Gut Mycobiome Dysbiosis Is Linked to Hypertriglyceridemia among Home Dwelling Elderly Danes," bioRxiv, 2020.

[2] H. F. Ahmad et al., "IDDF2020-ABS-0174 Onset of hypertriglyceridemia in relation to dietary intake, gut microbiome and metabolomics signatures among home dwelling elderly," gut, vol. 69, no. Suppl 2, pp. A21--A21, 2020.

[3] A. E. Kates et al., "Household Pet Ownership and the Microbial Diversity of the Human Gut Microbiota," Front. Cell. Infect. Microbiol., vol. 10, p. 73, Feb. 2020.

[4] J. K. Jarett, A. Carlson, M. Rossoni Serao, J. Strickland, L. Serfilippi, and H. H. Ganz, "Diets with and without edible cricket support a similar level of diversity in the gut microbiome of dogs," PeerJ, vol. 2019, no. 9, pp. 1-22, 2019.

[5] E. Mondo, G. Marliani, P. A. Accorsi, M. Cocchi, and A. Di Leone, "Role of gut microbiota in dog and cat's health and diseases," Open Veterinary Journal, vol. 9, no. 3. pp. 253-258, 2019.

[6] S. Z. N. Effa, S. J. Phang, and H. F. Ahmad, "Autoimmune Diseases and Gut Symbionts : The Unpopular Liaison," Malaysian J. Med. Heal. Sci., vol. 15, no. 13, pp. 165-172, 2019.

[7] T. Bo and K. D. Kohl, "Stabilization and optimization of host-microbe-environment interactions as a potential reason for the behavior of natal philopatry," Anim. Microbiome, vol. 3, no. 1, p. 26, 2021.

[8] A. R. Williams et al., "Dietary cinnamaldehyde enhances acquisition of specific antibodies following helminth infection in pigs," Vet. Immunol. Immunopathol., vol. 189, pp. 43-52, Jul. 2017.

[9] A. R. Williams et al., "A polyphenol-enriched diet and Ascaris suum infection modulate mucosal immune responses and gut microbiota composition in pigs," PLoS One, vol. 12, no. 10, pp. 1-21, 2017.

[10] H. F. Ahmad, "Improved methods for high yield genomic DNA of cat stools using DNeasy PowerSoil Pro Kit," protocols.io, 2021. [Online]. Available: https://www.protocols.io/view/improved-methods-for-high-yield-genomic-dna-of-cat-bp56mq9e.

[11] J. J. Kozich, S. L. Westcott, N. T. Baxter, S. K. Highlander, and P. D. Schloss, "Development of a Dual-Index Sequencing Strategy and Curation Pipeline for Analyzing Amplicon Sequence Data on the MiSeq Illumina Sequencing Platform," Appl. Environ. Microbiol., vol. 79, no. 17, pp. 5112-5120, 2013.

[12] H. F. AHMAD, "Malaysian Feline Microbiome Study," 2021.

[13] F. Binti and I. Hisham, "A Comparison of Gastrointestinal Microbial Communities between Indoor Cats and Outdoor Cats Farhana Ikmal Hisham," 2015.

[14] C. E. Older, A. B. Diesel, S. D. Lawhon, C. R. R. Queiroz, L. C. Henker, and A. Rodrigues Hoffmann, "The feline cutaneous and oral microbiota are influenced by breed and environment," PLoS One, vol. 14, no. 7, p. e0220463, Jul. 2019.

[15] F. Marciano and P. Vajro, "Oxidative Stress and Gut Microbiota," in Gastrointestinal Tissue: Oxidative Stress and Dietary Antioxidants, Elsevier Inc., 2017, pp. 113-123.

[16] F. A. Uzal et al., "Towards an understanding of the role of Clostridium perfringens toxins in human and animal disease," Future Microbiology, vol. 9, no. 3. Future Medicine Ltd., pp. 361-377, 2014.

[17] A. Kageyama and Y. Benno, "Catenibacterium mitsuokai gen. nov., sp. nov., a gram-positive anaerobic bacterium isolated from human faeces," Int. J. Syst. Evol. Microbiol., vol. 50, no. 4, pp. 1595-1599, 2000.

[18] K. Nishida, D. Sawada, Y. Kuwano, H. Tanaka, and K. Rokutan, "Health benefits of lactobacillus gasseri cp2305 tablets in 
young adults exposed to chronic stress: A randomized, double-blind, placebo-controlled study," Nutrients, vol. 11, no. 8, Aug. 2019.

[19] M. R. Foulquié Moreno, P. Sarantinopoulos, E. Tsakalidou, and L. De Vuyst, "The role and application of enterococci in food and health," International Journal of Food Microbiology, vol. 106, no. 1. pp. 1-24, Jan-2006.

[20] M. Torabinejad and R. E. Walton, Endodontic Principles and Practice 4th Ed - Torabinejad. 2009.

[21] R. O. S. Silva and F. C. F. Lobato, "Clostridium perfringens: A review of enteric diseases in dogs, cats and wild animals," Anaerobe, vol. 33, pp. 14-17, 2015.

[22] E. N. Bermingham et al., "The Fecal Microbiota in the Domestic Cat (Felis catus) Is Influenced by Interactions Between Age and Diet; A Five Year Longitudinal Study," Front. Microbiol., vol. 9, p. 1231, Jun. 2018. 